\title{
ISOLATED NONCOMPACTED MYOCARDIUM IN AN ELDERLY PATIENT
}

doi: 10.1590/S1807-59322008000400029

\author{
Eduardo de Paula Miranda, ${ }^{\mathrm{I}}$ Lucas Alverne Freitas Albuquerque, ${ }^{\mathrm{I}}$ Rubem Abitbol Menezes Júnior, ${ }^{\mathrm{II}}$ Ântonio Welington \\ Silva, ${ }^{\mathrm{III}}$ Lúcia de Sousa Belém, ${ }^{\mathrm{III}}$ Fernando Pinheiro Ramos ${ }^{\mathrm{III}}$
}

\section{INTRODUCTION}

Noncompaction of the myocardium (NCM) is a rare disorder that is characterized by prominent myocardial trabecularizations and deep intertrabecular recesses, leading to a spongy appearance of the myocardium.

In the first month of normal intrauterine development, the myocardium consists of a mesh of muscle fibers. In this mesh, trabeculae alternate with recesses, which provide the blood supply to the cardiac muscle through communication with the ventricular cavity. During the fifth to the eighth week of development, these recesses are supposed to turn into capillaries as the ventricular myocardium gradually compacts. $^{3,4}$

Although the exact mechanisms that generate NCM remain unclear, it has been suggested that an arrest of cardiac development during the compaction of myocardial fibers may lead to the persistence of multiple trabeculations within the ventricular myocardium. ${ }^{1,2}$

\section{CASE REPORT}

A 76-year-old woman with a 5-month history of progressive dyspnea presented with significant worsening one week prior to admission. She had no previous history of cardiomyopathy, hypertension, diabetes, or Chagas disease. She denied alcohol or tobacco use, and had no family history of cardiovascular disease.

Upon physical examination, the patient was afebrile

\footnotetext{
I Universidade Federal do Ceará - Fortaleza/CE, Brazil.

"I Faculdade de Saúde, Ciências Humanas e Tecnológicas do Piauí-Teresina/ PI, Brazil.

III Hospital de Messejana Dr. Carlos Alberto Studart Gomes - Fortaleza/ CE, Brazil.

Email: dudu308@yahoo.com.br
}

(T $\left.36^{\circ}\right)$, with a heart rate of $72 \mathrm{bpm}$, respiratory rate of 22 breaths/min, and a blood pressure of $110 / 60 \mathrm{mmHg}$. Overall, the patient appeared well, but was in mild respiratory distress. Her heart rhythm was regular, with a normal S1, a prominent S2, an audible S3 and a III/VI systolic murmur that was loudest at the left sternal border and at the 5th midclavicular intercostal space.

Bilaterally, her lungs had coarse rales at the bases. Her abdomen was soft and without tenderness, with a palpable liver $3 \mathrm{~cm}$ beneath the right costal border. She had $3+$ peripheral edema of both legs.

The following laboratory values were obtained: $\mathrm{Hb} 14.9$ g/dl; Hematocrit 44.2\%; Urea $161 \mathrm{mg} / \mathrm{dL}$ (BUN 75 mg/dL); creatinine 2,3 mg/dL; sodium $134.4 \mathrm{mEq} / \mathrm{L}$; potassium 4.3 $\mathrm{mEq} / \mathrm{L}$; serum glucose $98 \mathrm{mg} / \mathrm{dl}$; international normalized ratio (INR) 1.96; activated partial thromboplastin time (PTT) 32.8 seconds; TSH $9.25 \mu \mathrm{UI} / \mathrm{ml}$ (normal 0.35 - 5.5 $\mu \mathrm{UI} / \mathrm{ml}$ ), T3 $1.06 \mathrm{ng} / \mathrm{ml}$ (normal $0.6-1.81 \mathrm{ng} / \mathrm{ml}$ ), and T4 $1.49 \mathrm{ng} / \mathrm{dl}$ (normal $0.89-1.76 \mathrm{mg} / \mathrm{dl}$ ). Her urinalysis was unremarkable.

Electrocardiography showed atrial fibrillation with a left bundle branch block (Figure 1). The chest radiograph revealed a significant cardiac area enlargement (Figure 2).

Three-dimensional transthoracic echocardiograpy (TTE) demonstrated the following: moderate enlargement of the left ventricle (LV), severe enlargement of the left atrium (LA) at $5.7 \mathrm{~cm}$ and a large right atrium (RA). In addition, the patient was found to have severe mitral regurgitation (Figure 3), moderate tricuspid regurgitation, pulmonary hypertension (systolic pressure of the pulmonary artery $=52$ $\mathrm{mmHg}$ ), and patent foramen ovale with minimal right-to-left shunting. Furthermore, the TTE showed numerous prominent trabeculations, and deep intertrabecular recesses (Figure 4 and 5), along with diffuse and moderate hypokinesia of the LV with LV systolic function mildly impaired (EF = 


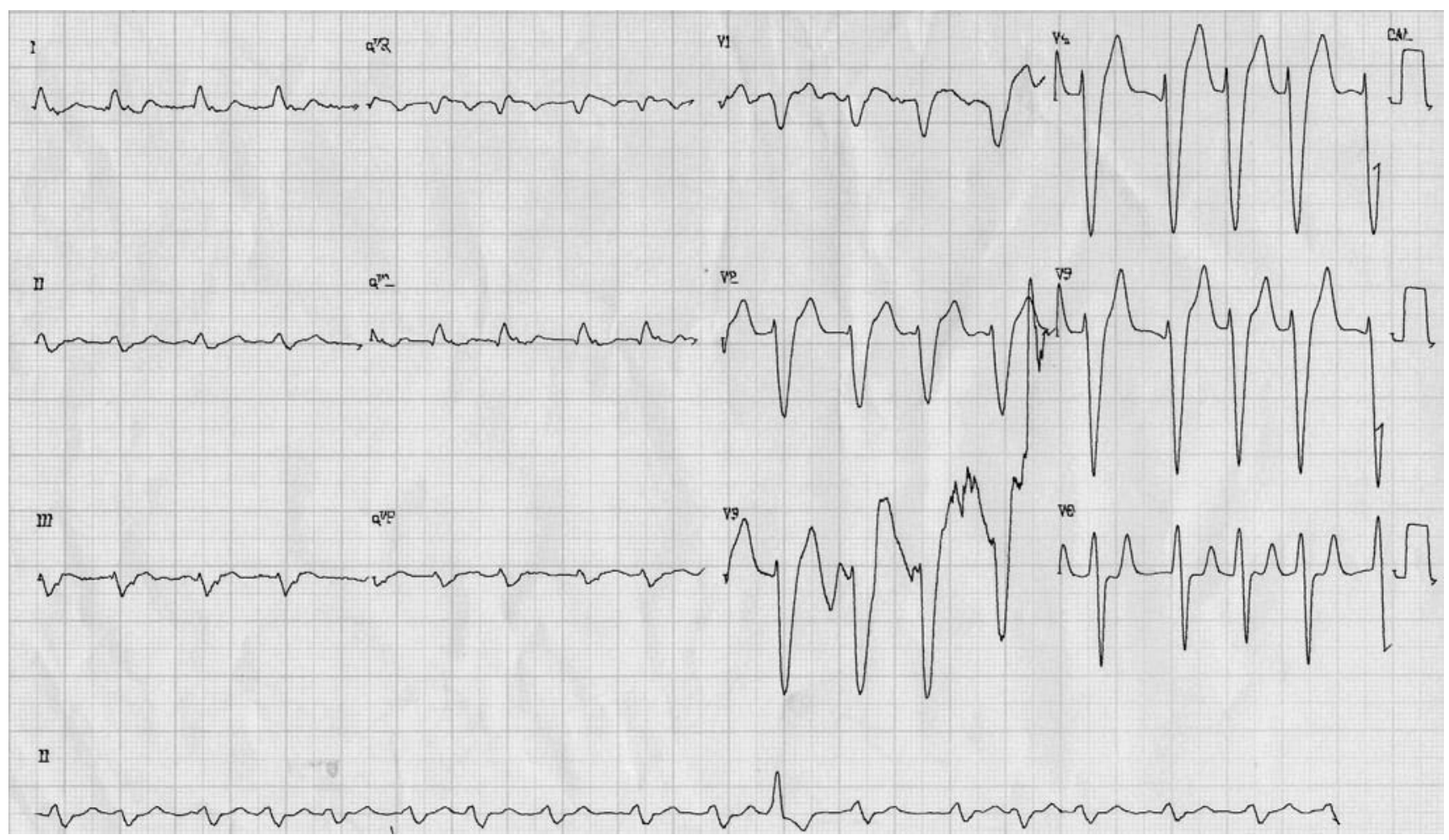

Figure 1 - Eletrocardiography at admission

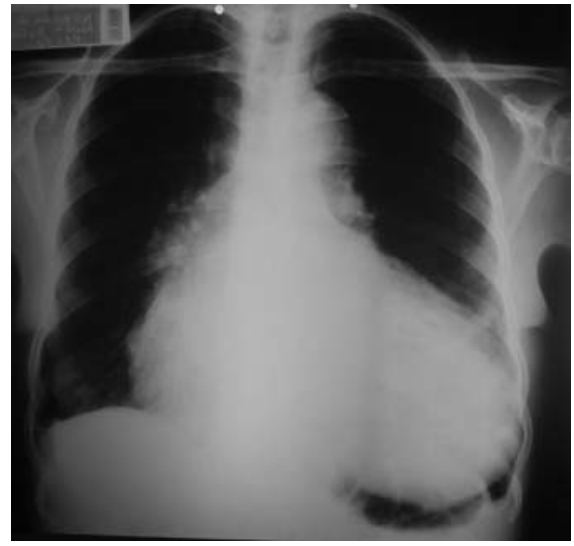

Figure 2 - Chest X-ray demonstrating considerable cardiomegaly

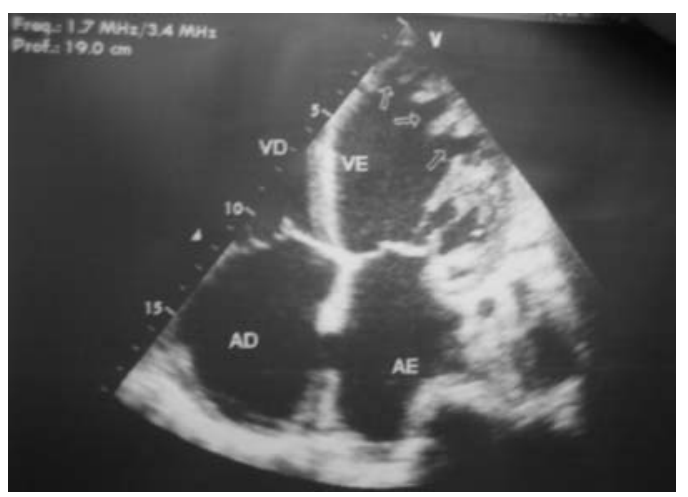

Figure 4 - Transthoracic achocardiography at apical 4-chamber (AFC) view showing patente foramen ovale, presence of numerous prominent trabeculations and deep intertrabecular recesses. $\mathrm{AD}$ - right atrium; VC - right ventriculum; AE - left atrium; VE - left ventriculum

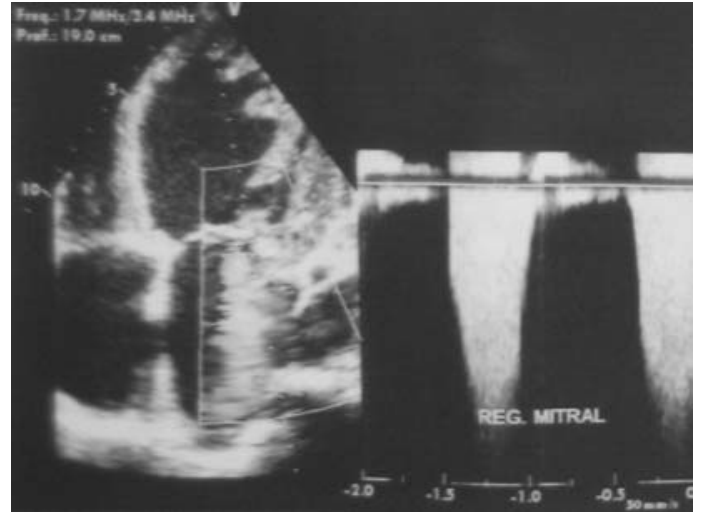

Figure 3 - Transthoracic echocardiography showing severe mitral regurgitation

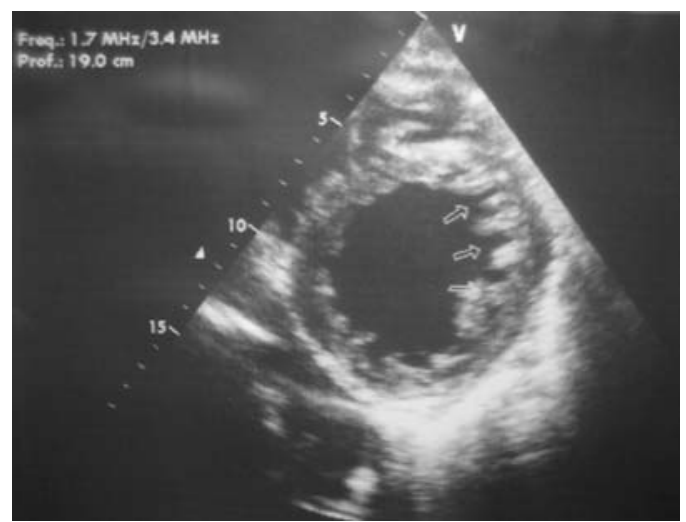

Figure 5 - Short axis view of the apex revealing prominent trabeculations and intertrabecular recesses at another axis 
49\%). According to the echocardiographic criteria, isolated noncompacted myocardium (INCM) was diagnosed.

Coronary angiography was performed to exclude other etiologies such as ischaemic cardiomyopathy and showed coronary arteries with mild atheroma lesions and a left ventricle with a trabecular and hypertrophic pattern.

After nine days, the patient was discharged with mild limitation of activity (New York Heart Association II), and prescribed the following medications: an angiotensinconversing enzyme inhibitor, an aldosterone antagonist, a beta-adrenergic blocker, and oral anticoagulant therapy.

\section{DISCUSSION}

$\mathrm{NCM}$ is a rare entity, usually diagnosed in the pediatric population and is associated with other structural congenital malformations of the heart, such as obstruction of the right or left ventricle outflow tract. It is believed to be genetically transmitted, and there is a male predominance ranging from $56 \%$ to $82 \%$ among the reported familial cases. ${ }^{1,3}$

Isolated noncompaction of the myocardium (INCM), defined by the absence of any other structural cardiac abnormalities, is an even rarer form of the entity, with only a few reports in the literature..$^{1-3}$

Our patient is a rather unusual case of INCM, since her diagnosis was established at age 76. This is significantly outside of the established age range of adults with this disorder, which is 37 to 43 years old. ${ }^{4,5}$ In the literature, we identified only seven reported cases of INCM described in patients older than 70 years, ${ }^{15,16}$ and this case represents one of the oldest patients ever reported. There are several explanations for this late diagnosis: 1) symptoms may manifest late since there is significant variability in the natural course of INCM; 2) This patient was very sedentary, perhaps rendering the symptoms less prominent; 3) The patient lived in a rural area that had restricted access to the healthcare system, so she may have suffered from mild symptoms of heart failure that went unnoticed for a significant amount of time.

The patient met echocardiographic criteria for the diagnosis of INCM:1,6,8,9 1 ) The presence of multiple echocardiographic trabeculations, particularly in the apex and free wall of the LV; 2) Multiple deep intratrabecular recesses communicating with the ventricle cavity, as demonstrated by color Doppler imaging; 3) a 2-layered structure of the endomyocardium with an increased noncompacted to compacted ratio ( $>2.0$ in adults, $>1.4$ in children); 4 ) the absence of another coexisting heart anomaly, including aortic and pulmonary valve abnormalities and coronary disease. Although there is variability between the authors in the echocardiographic criteria for diagnosing INCM $^{13}$, we believe that the criteria used have good accuracy.

The mitral valve affliction is believed to be secondary to the ventricular dysfunction and dilatation caused by INCM. ${ }^{1}$

The clinical aspects of INCM are not yet well-defined, as they are not specific to this cardiomyopathy and are highly variable. Patients may be asymptomatic or may suffer severe cardiac dysfunction. ${ }^{1,8}$ Tachyarrhythmias such as atrial fibrillation, supraventricular tachycardia, Wolff-ParkinsonWhite syndrome, and ventricular tachycardia, or conduction defects such as atrioventricular or bundle branch block, can also be observed. Cardioembolic complications, resulting from atrial fibrillation or from the formation of thrombi in the ventricular trabeculae, are frequent. ${ }^{8}$ Therefore, in addition to treatment for congestive heart failure and arrhythmias, anticoagulation therapy is often recommended because of the risk of systemic emboli.

In this case, the patient's atrial fibrillation was considered chronic. It was treated with beta-blockers and anticoagulant therapy to ensure rhythm control and to prevent clot formation. ${ }^{11,12}$

The increasing number of reported cases of INCM, the high variability of its clinical manifestations, and the diagnosis of INCM in an elderly patient lead us to believe that this disease is actually underestimated.

Further research is needed to solve current controversies regarding diagnostic criteria, nomenclature, prognosis, origin and pathogenesis. Some remaining questions include whether or not the presence of congenital heart anomalies should exclude NCM, and whether cases diagnosed in young children or in adults represent subgroups of the disease.

\section{REFERENCES}

1. Chin TK, Perloff JK, Williams RG, Jue K, Mohrmann R. Isolalated noncompaction of left ventricular myocardium: a study of eight cases. Circulation. 1990;82:507-13.

2. Corrado G, Santarone M, Miglierina E, Beretta S, Frattini T, Tadeo G. Isolated noncompaction of the ventricular myocardium. A study in an adult male and literature review. Ital Heart J. 2000;1:372-5.
3. Dusek J, Bohuslav O, Duskova M. Posnatal persistence of spongy myocardium with embrionicbblood supply. Arch Pathol. 1975;99:3127.

4. Espinola-Zavaleta N, Soto ME, Castellanos LM, Játiva-Chávez S, Keirns C. Non-compacted cardiomyopathy: clinical-echocardiographic study. Cardiovascular Ultrasound. 2006;4:35. 
5. Murphy RT, Thaman R, Blanes JG, Ward D, Sevdalis E, Papra E, et al. Natural history and familial characteristics of isolated left ventricular non-compaction. European Heart Journal. 2005;26:187-92.

6. Ritter M, Oechslin E, Sutsch G, Attenhofer C, Schneider J, Jenni R. Isolated noncompaction of the myocardium in adults. Mayo Clin Proc. 1997;72:26-31.

7. Elias J, Valadão W, Kuniyoshi R, Queiroz A, Peixoto CA. Miocárdio não compactado isolado. Arq Bras Cardiol. 2000;74:253-7.

8. Weiford BC, Subbarao VD, Mulhern KM. Noncompaction of the ventricular Myocardium. Circulation. 2004;109:2965-71

9. Salemi VMC, Araujo AQ, Arteaga E, Mady C. Pitfalls in the echocardiographic diagnosis of isolated non-compaction of the ventricular. Heart. 2005;11:1382.

10. Kohli SK, Pantazis AA, Shah JS, Adeyemi B, Jackson G, McKenna WJ, et al. Diagnosis of left-ventricular non-compaction in patients with left-ventricular systolic dysfunction: time for a reappraisal of diagnostic criteria? European Heart Journal. 2008;29:89-95.
11. Soler R, Rodriguez E, Monserrat L, Alvarez N. Magnetic resonance imaging of subendocardial perfusion deficits in isolated left ventricular noncompaction. J Comput Assist Tomogr. 2002;26:373-5.

12. Conraads V, Paelinck B, Vorlat A, Vorloit A, Goethals M, Jacobs W. Isolated non-compaction of the left ventricle: a rare indication for transplantation. J Heart Lung Transplant. 2001;20:904-7.

13. Giafana P, Badano LP, Faganello G, Tosoratti E, Fioretti PM. Additive value of contrast echocardiography for the diagnosis of noncompaction of the left ventricular myocardium. Eur J Echocardiogr. 2006;7:6770

14. Lin ML, Connelly K, Prior D. An unusual cause of heart failure identified by echocardiography in an octogenarian. The European Journal of Heart Failure. 2005;7:99-102.

15. Palloshi A, Puccetti P, Fragasso G, Agricola E, Mellone R, Del Maschio A, et al. Elderly manifestation of non-compaction of the ventricular myocardium. J Cardiovasc Med. (Hagerstown) 2006;7:714-6. 